\title{
PROMOTING THE WELL-BEING OF HIGHER EDUCATION: RE- ENGINEERING OF TRANSNATIONAL NURSING EDUCATION
}

\author{
V. Naidoo* \\ e-mail: vasanthrien@dut.ac.za
}

\author{
M. N. Sibiya* \\ e-mail: nokuthulas@dut.ac.za \\ *Faculty of Health Sciences-Nursing \\ Durban University of Technology \\ Durban, South Africa
}

\section{ABSTRACT}

Globalization of nursing education has allowed for greater autonomy and inter-connectedness of the nursing profession and South African universities have, in recent years, engaged in international partnerships, influencing the delivery and facilitation of transnational nursing education (TNE) or cross-border nursing education. This has increased international student enrolment, particularly from other African nations and whilst, much has been written about international partnerships relevant to other forms of higher education, minimal research has been done and reported on for cross-border nursing education and partnerships. This provided the rationale for this study to examine and explore TNE challenges by using actual participant examples and experiences. Using a qualitative, multiple case-study approach to sample local, national and international nursing education institutions, academic leaders and nurse graduates, the study identified challenges and best operating practices in TNE implementation. With the main aim being to highlight regulatory, administrative and quality assurance factors in TNE delivery, findings revealed that these programmes are still challenged alluding to it being a "for profit" arrangement. The study, further concluded that for a TNE programme to be consistently high in standard and globally competitive, a culturally and socially inclusive teaching and learning curriculum had to be devised to allow students to fulfil the respective requirements of their academic programmes. This will further increase the credibility of the educational institution and the country's higher education system.

Keywords: cross-border education, transnational nursing education (TNE).

\section{INTRODUCTION}

Higher education constitutes a vital component of a country's culture and knowledge, serving as a conduit for the sustainability of national values and educational goals. It also plays an important role in a country's economy the generating new knowledge through research and 
innovation. According to the South African policy draft on internationalization, the rationale for higher education internationalization includes various dimensions, such as positioning of the higher education system to be competitive in a globalized world, advancing the quality of higher education, benefitting society and enhancing opportunities for higher education to contribute to the public good (Department of Higher Education and Training 2017, 19). According to Sooryamurthy $(2013,1)$, South Africa, is considered a knowledge hub on the African continent and is a much sought-after destination for international educational opportunities and research collaboration. As a result of collaboration, higher education, particularly nursing education, is no longer provided solely within national borders (Collins and Hewer 2014, 150).

The last two decades has seen internationalization of nursing education becoming a priority of academic institutions' strategic plans and visions, thereby influencing the delivery and facilitation cross-border nursing education (Baumann and Blythe 2008, 4). Cross-border nursing education includes all higher education nursing programmes, or educational offerings in which student nurses are in a country different from the one where the awarding institution is based and apart from increasing the educational institution's profile, they provide openings for intercontinental business opportunities influencing the country's economy (Knight 2006, 1).

The National League for Nursing (NLN), which is a nursing organization representing nursing education programmes across the global spectrum of higher education and health care organizations, endorses faculty development and global networking opportunities, agreeing that international collaborations go beyond crossing borders as they are an integral part of the countries higher education system (Lafond and Van Hulle Vincent 2012). The NLN further recommended TNE as a means to developing competent educators and students that provided them with exposure, experience and growth. According to Burnett (2008), increased cooperation, effective interpersonal skills and teamwork promoted broader cross-border collaboration amongst stakeholders. Knight $(2004,21)$ suggests that competent, well-motivated and sustainable professional workforce was vital for the success of cross-border initiatives. Armstrong and Rispel $(2015,6)$ agree that it is important to understand healthcare and education issues in a global context since international partnerships provide changes in professional roles across national and international boundaries.

Thus far, South African cross-border nursing education initiatives have been twofold. Firstly it addresses the global shortage of trained nurses and secondly, it suggests a way to promote global understanding and sharing of best practices in nursing education and practice. In South Africa, the Department of Higher Education and Training (DHET) has acknowledged that the internationalisation of higher education has grown over the past two decades and 
considers it a reflection of globalisation, as well as of South Africa's return to the international community. The DHET has recently submitted a policy draft on internationalization, emphasizing the associated risk-benefit ratio and acknowledging the urgent call for a national policy framework to uphold the rigorous standards of academic quality whilst promoting higher education well-being (Department of Higher Education and Training 2017, 19). Thus, the impetus for this research art, that sought to identify functional deficits of cross-border nursing education programmes and illustrate some questions that transnational nursing education raises in pedagogy such as curriculum design, teaching and assessment strategies. Edmonds (2010, 546) states that much has been written about other higher education international partnerships, revealing that cross-border nursing education in higher education is an under-researched area. It is within this context that the authors of this article wrote from a local, national and international perspective, explored nursing education institutions' quality assurance practices and examined academic leader's and graduate's TNE experiences. This article therefore, hopes to address the following questions:

1. Are South African transnational nursing projects "healthy" enough to ensure the wellbeing of the higher education system?

2. Are current cross-border nursing projects structurally and practically sound to be part of the global outfit?

3. Can the introduction of robust quality assurance practices re-engineer cross-border nursing initiatives, thereby strengthening internationalization of nursing education?

\section{REVIEW OF THE LITERATURE}

\section{Transnational education}

The terms "cross-border education", internationalization of education, and "transnational education" are often used interchangeably and are synonymous with "offshore education", "borderless education" or "international collaborative education." (Knight 2006, 1-28). Internationalization of higher education remains a key focus area as higher education institutions endeavor to stimulate the country's intellectual growth (Wilson 2002, 417). Havukainen and Ikonen (2013) maintain that international collaborations in health sciences is necessary to influence a country's social and economic progress and the country's health economy. The benefits of a knowledge based society makes cross-border nursing education significant and in some cases a necessity to help grow a country's economy (Chetro-Szivos 2010, 5-22). However, certain factors that question the social and curricular relevance, 
institutional quality and global competitiveness of the programme still remain. Rumbley, Altbach and Reisberg (2012, 3-26), maintain that cross-border projects have influenced the higher education sector to focus on increasing a diversified curriculum, staff and student population, seeking to effectively prepare students to serve in the global world. The same study found that very few countries or higher education institutions remained immune to the call to participate in cross-border programmes concluding that, cross-border programme implementation is subject to debate, mainly because the educational standards between countries still remained fragmented and compartmentalized (Knight 2004, 21).

\section{Transnational nursing education}

Tertiary institutions, offering nursing programmes consider TNE this as a dynamic approach to building mutual understanding, assisting other countries in capacity development, generating revenue for the country and the cross-border provider. Bauman and Blythe (2008, 4-5) state that some countries see TNE as a way to drive significant levels of foreign investment and funding models into the country. Depending on the need to address the skills gap in a particular country, TNE is used to produce graduates to function within the much needed labour market and the structure of the TNE programme is often suited to plug these skills gaps (Chetro-Szivos 2010, 5-22). These projects also answer the need for skilled nurse practitioners in response to the demands of a globalized society Zeleza (2012, 4-27).

\section{Delivery and facilitation of TNE}

Dominguez-Whitehead and Sing $(2015,77-95)$, reveal that an enabling factor to redesigning approaches and strategies of learning and teaching in cross-border education would be to emphasize a sense of connection and relevance to the country's demographics. Another study conducted by Burnett $(2008,16)$ revealed that it was concerning that there was minimal literature reported on the benefits of the "importing" and "exporting" of education services worldwide, stating that it was imperative for cross-border nursing practices to be reviewed through a global lens. The same study suggested a need to scrutinize quality assurance mechanisms such as governance models and operational practices to identify and rectify challenges in programme delivery. Nguyen $(2012,84-87)$ agreed that other fundamental processes such as communication strategies, conflict resolution policies, environmental factors and adequacy of resources influenced the facilitation and delivery of TNE programmes.

\section{Monitoring and evaluation of TNE}

Nursing is a regulated profession, in which lives depend on the possession of specific 
competencies. Baumann and Blythe $(2008,4)$ examined the cross-border education challenges faced by healthcare workers, revealing that although the world has witnessed significant growth in cross-border nursing programmes in recent times, there is an urgent need to monitor and evaluate the standard of programmes that are offered. Knight $(2006,2)$ agrees and further states that cross-border education can also be a costly exercise with little reward for the provider if not governed by proper quality assurance mechanisms such as policies and protocols. The same author noted that, although there are different stakeholders involved in designing and managing TNE programmes, the challenges around the academic programme design and relevance need to be addressed.

Adam (2001, 4-15), found that organizational policies and standards were necessary to govern the cross-border recruitment and selection processes and they are influential in shaping governments' regulatory frameworks and quality assurance processes pertaining to crossborder nursing programmes. According to Villanueva $(2012,47)$, the importance of TNE projects having clearly articulated rationale, objectives, strategies and measurable outcomes, cannot be overstated. The author further states that, well defined quality assurance rationale and specific goals will allow objectives to be turned into action through the articulation and implementation of strategies that guide the TNE process delivery. This is in keeping with a policy brief issued by the World Health Organization (WHO). The WHO strives to ensure that all countries meet the global standards for initial nursing education programmes and has stated that it is the task of policy-makers in each country to determine adherence to policies and protocol that surround the issues of nursing education such as co-ordination and facilitation (WHO 2013, 1-3). The organization is adamant that receiving countries must have in place the requisite policies, protocols and structures to effectively guide and manage registration and accreditation of foreign education programmes related to health, arguing that this should be applicable to all state, private and commercial nursing education institutions that deliver TNE programmes.

\section{Cultural diversity in TNE}

Cultural diversity is only one of the many challenges facing the transnational education system today and there is a need for providers to be culturally sensitive as they acknowledge that delivery and acceptance of TNE is influenced by social, cultural, and environmental factors (Ralarala, Pineteh and Mchiza, 2016, 231). The differences between the degree awarding institution's general goals, student characteristics and sociocultural dimensions, have often been identified as compounding problems in cross-border education (Adamiak and Sauls 2017, 230-248). Van Niekerk and Schmidt (2016, 196-214) agree that although student success is of 
paramount importance for any higher education institution throughout the world, but the process of teaching and learning is adversely affected, when cultural diversity and communication barriers become apparent.

\section{Quality assurance in cross-border programmes}

Quality assurance in a tertiary education system refers to the policies, procedures and protocols necessary to ensure that programme quality is maintained and enhanced. Consequently, Fearnside and Chung $(2017,81)$ ask the following question: Why does cross-border quality assurance matter? They also respond by stating that educational institutions function in globally competitive markets and instructional programmes need to be developed so that they are locally and internationally relevant, whilst preparing the student for entry into the globalized world. Countries around the world have different quality assurance systems for their education delivery, as necessitated by their unique national contexts and quality assurance systems play a vital role in cross-border nursing education programmes, ensuring academic criteria such as course material, monitoring and evaluation strategies and staff calibre are of a high academic standard. Students involved in cross-border programmes often categorize quality indicators from an academic and non-academic viewpoint. Academic staff, programme quality and university's reputation are considered academic factors and factors such as financial assistance, counselling, support services, and job placement services are considered non-academic quality indicators (Gamage et al. 2008). China, a country involved in many international nursing education partnerships initiated comprehensive health reforms in 2009 in an attempt to improve the health of its nation. It was reported that education was the best health outcome and quality indicator in improving the country's health economy (Lee, Chiang and Liu 2017). The same study viewed China's educational reform as being progressive and a best operating practice.

\section{Theoretical framework that guided the study}

Figure 1 is adapted from a model drawn up by the National Assessment and Accreditation Council (NAAC) of India. This model serves as a basis for accreditation of higher education in that country. The schematic diagram, illustrates the relevance of guidelines, policies and protocols in generating quality standards in cross-border nursing education.

\section{RESEARCH PROBLEM}

The nursing profession is a clinical and technical speciality that depends on correlation of theory with practice whereby learning outcomes are consistently controlled and governed by best operating practices. Educational institutions embarking on cross-border nursing programs have 


\section{EFFECTIVE IMPLEMENTATION OF TRANSNATIONAL NURSE EDUCATION LEADING TO POSITIVE GLOBAL, INDIVIDUAL, ECONOMIC, SOCIAL AND EDUCATIONAL IMPACT}

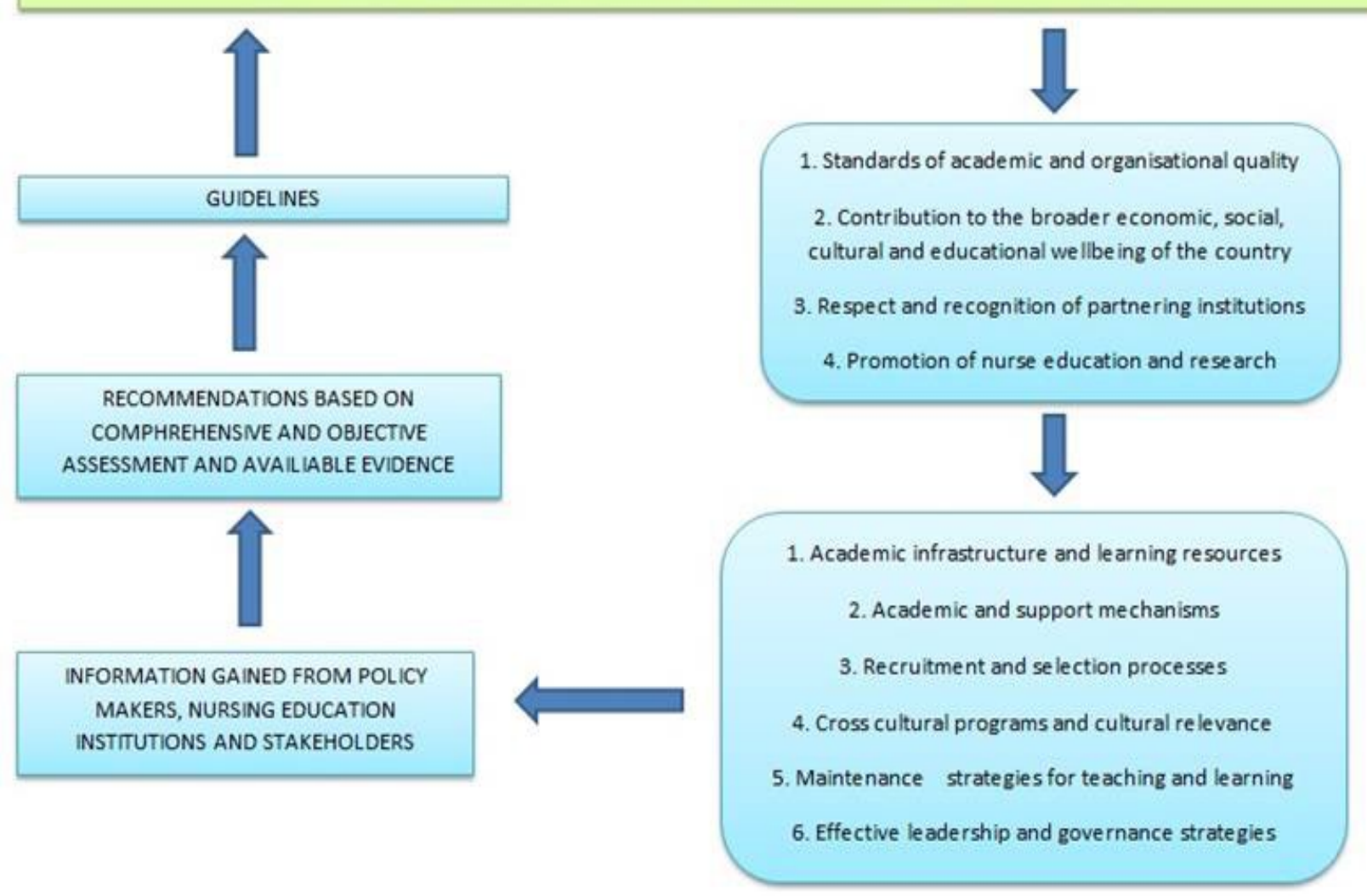

Figure 1: Implementation of TNE guidelines having a positive effect on its service delivery and implementation (Source: adapted from the National Assessment and Accreditation Council (NAAC) for Quality and Excellence in Higher Education in India)

primarily focused on the development of language competencies and cultural diversity requirements for entry to and completion of a programme of study. As evidenced by the literature review, cross-border nursing education and training can be challenged by regulatory, administrative and quality assurance factors that influence its programme delivery. Although international collaborations endeavour to maintain high academic standards in TNE, there is still a need to re-engineer, revise and adapt curricular content, learning, and teaching and assessment practices to aid the stakeholders of TNE. It is against this background that the authors sought to explore the inherent challenges in cross-border nursing education and maximized data collection opportunities, by sampling participants from both national and international settings.

\section{PURPOSE}

This research article aims to share insight, findings and discuss key issues related to crossborder nursing education experiences and practices. It is hoped that this will offer guidance to 
forthcoming as well as existing higher education curriculum developers who plan to engage in national or international educational partnerships.

\section{SIGNIFICANCE}

Cross-border education can typically strengthen a country's tertiary education system and to increase the capacity development of its highly skilled human capital. The findings of this study also offer guidance to academics and institutions on the quality and relevance of their educational offerings leading to organizational learning and system change. The identified challenges affecting the facilitation and delivery of cross-border nursing education programs can also act as levers to improving service quality of existing and future cross-border programs.

\section{SAMPLING}

Purposive sampling is defined by Polit and Beck $(2012,739)$ as a process whereby the researcher selects participants because of their characteristics. The sample utilized in this study, focused purposively on the practices, perspectives and experiences of both national and international higher education institutions, academic leaders and TNE graduates (see Table 1 and Table 2).

Table 1: The following table illustrates the academic leaders' demographic profile

\begin{tabular}{|c|c|c|c|c|}
\hline Participant & Position & Role Responsibility & Program & Continent \\
\hline No. 1 & $\begin{array}{c}\text { Honorary Associate } \\
\text { Professor }\end{array}$ & $\begin{array}{c}\text { Co-ordination and } \\
\text { Facilitation of Transnational } \\
\text { Nursing Programmes }\end{array}$ & $\begin{array}{c}\text { Critical Care, Advanced } \\
\text { Midwifery, Nurse }\end{array}$ & Africa \\
\hline No. 2 & $\begin{array}{c}\text { Department Head- } \\
\text { Nursing }\end{array}$ & $\begin{array}{c}\text { Programme Facilitator } \\
\text { Masters supervision, } \\
\text { Critical Care Nursing }\end{array}$ & Africa \\
\hline No. 3 & Lecturer & Programme Facilitator & Critical Care Nursing & Africa \\
\hline No. 4 & Training Officer & $\begin{array}{c}\text { Programme } \\
\text { Administrator/Clinical } \\
\text { Coordinator }\end{array}$ & $\begin{array}{c}\text { Medical and Surgical } \\
\text { Nursing Operating } \\
\text { Theatre and ICU }\end{array}$ & Asia \\
\hline No. 5 & Department Head- & $\begin{array}{c}\text { Programme Coordinator } \\
\text { Nursing }\end{array}$ & $\begin{array}{c}\text { Post Graduate Research } \\
\text { Coordinator }\end{array}$ & Australia \\
\hline No.6 & Unit Manager & Clinical Coordinator & $\begin{array}{c}\text { Medical and Surgical } \\
\text { Nursing Operating } \\
\text { Theatre and ICU }\end{array}$ & Asia \\
\hline
\end{tabular}

Table 2: The following table illustrates the graduates' demographic profile

\begin{tabular}{|c|c|c|c|c|}
\hline Participant & Position & Programme & $\begin{array}{c}\text { Country } \\
\text { of Origin }\end{array}$ & Host Country \\
\hline No. 1 & Registered Nurse & $\begin{array}{c}\text { Masters in Nursing } \\
\text { Science }\end{array}$ & Canada \\
\hline No. 2 & Registered Nurse & $\begin{array}{c}\text { Masters in Nursing } \\
\text { Science }\end{array}$ & Asia & Saudi Arabia \\
\hline No. 3 & Registered Nurse & Critical Care Nursing & Asia & Saudi Arabia \\
\hline No. 4 & Registered Nurse & Critical Care Nursing & Asia & Australia \\
\hline No. 5 & Registered Nurse & Critical Care Nursing & India & Australia \\
\hline
\end{tabular}




\begin{tabular}{|c|c|c|c|c|}
\hline Participant & Position & Programme & $\begin{array}{l}\text { Country } \\
\text { of Origin }\end{array}$ & Host Country \\
\hline No. 6 & Registered Nurse & $\begin{array}{c}\text { Operating Theatre } \\
\text { Nursing }\end{array}$ & India & Canada \\
\hline No. 7 & Registered Nurse & $\begin{array}{c}\text { Operating Theatre } \\
\text { Nursing }\end{array}$ & Asia & United Kingdom \\
\hline No. 8 & Registered Nurse & $\begin{array}{l}\text { Operating Theatre } \\
\text { Nursing }\end{array}$ & Asia & Canada \\
\hline No. 9 & Registered Nurse & Critical Care Nursing & Seychelles & Kenya \\
\hline No. 10 & Registered Nurse & Critical Care Nursing & Seychelles & Kenya \\
\hline
\end{tabular}

\section{SETTING}

This qualitative research study, in the form of a multiple case study design, utilised selected learning environments of the participating higher education institutions. Permission was sought, granted and approved by the participating institutions and interviews were scheduled and conducted at the time and convenience of the academic institution and participant.

\section{DATA COLLECTION}

The following data collection methods were utilized in this study:

\section{Interviews}

Interview questions were designed to address the research questions and focused on organizational structures, governance and quality assurance processes related to the facilitation of TNE. All interviews were scheduled for thirty to forty-five minutes for each participant and audiotaped to provide an accurate record of the participant's comments. The number of interviews was guided by data saturation.

\section{Record reviews}

Documentation such manuals, guidelines or brochures was utilised to provide insight into institutional policies or processes (see Table 3). This enhanced the data collection process by corroborating with participants' interviews.

Table 3: Types of documents that were utilized during the record review process

\begin{tabular}{|l|l|}
\hline 1 & Documents that described the vision, mission and purpose of cross-border nursing education. \\
\hline 2 & $\begin{array}{l}\text { Documents that described how the institution managed cross-border nursing education quality } \\
\text { assurance }\end{array}$ \\
\hline 3 & $\begin{array}{l}\text { Documents that described how the institution develops and reviews cross-border programs and } \\
\text { curricula. }\end{array}$ \\
\hline 4 & \begin{tabular}{l} 
Documents that described how the institution evaluated and supported staff development. \\
\hline 5
\end{tabular} \\
\hline 6 & $\begin{array}{l}\text { Documents that described how the institution assessed monitored and supported transnational } \\
\text { student learning and teaching. } \\
\text { any other documentation that made reference to transnational students' learning and teaching, such }\end{array}$ \\
\hline
\end{tabular}




\section{DATA ANALYSIS}

Using thematic analysis, the researcher analysed the information obtained from the interviews. The qualitative data was transcribed from the audio recorder into a written format and then compared and read against the field notes for clarity. According to Polit and Beck $(2012,556-$ 560 ), the process of data analysis is described as a complex action of moving back and forth between data and concepts and as well as between description and interpretation. Tesch's open coding approach of data analysis was used to get an understanding of the conceptual and contextual issues. Data analysis revealed that cultural diversity and lack of quality assurance processes were some of the challenges TNE environment that affected successful implementation of its programme.

\section{TRUSTWORTHINESS}

The qualitative nature of this study allowed for the principles outlined by Lincoln and Guba's strategies of credibility, transferability, dependability and confirmability to be applied to enhancing trustworthiness Credibility in this study was achieved by accurate description of the study's parameters such as whom, where and when (Polit and Beck 2012, 584-587). Participants were purposively sampled and information was collected until data saturation was achieved. Transferability was promoted in this study by ensuring that and the research process was accurately described to all participants. Descriptions regarding the process of data gathering, data analysis and interpretation, attained the principle of dependability, whilst voice recordings and field notes increased the confirmability of the research.

\section{ETHICAL CONSIDERATIONS}

Ethical clearance was obtained from the University Institutional Research Ethics Committee and written consent was obtained from all participants, who made an informed, voluntary decision to participate in the study.

\section{FINDINGS}

\section{Identified themes}

Identified themes in this study reflected the participants' journey through the transnational nursing experience from the viewpoints of academia and TNE graduates and the actual responses as indicated became the raw data for analysis. The following are some of the participant responses that lent itself to the formation of the themes and sub-themes in this study. 


\section{ACADEMIC LEADER RESPONSES}

\section{Theme 1: Recruitment and selection processes in TNE}

Information received from participants on the export and import of transnational nurse education reflected that partnering countries have collaborative agreements with a view to mutual gains. There appeared to be no centralized selection, recruitment or registration process. Institutional internal policies often dictated selection criteria.

"A situational analysis is always conducted first before a project is implemented in any country. The curriculum is always adjusted and contextualized to the host country to cater for e their ways of doing things and the disease profile of the country." Academic leader 1.

\section{Theme 2: Regulation and control teaching / learning outcomes}

The study concluded that effective and appropriate quality assurance policies and practices are vital during any recruitment and selection process. Participants aired their views as follows:

"Students getting accepted into a higher education institution and having the credits transferred, means we are meeting standards that are being set by the administration of another institution abroad." Academic leader 3.

\section{Theme 3: TNE academia and student support structures}

Some participants stated that nurse educators felt incompetent at times, largely due to them being unable to manage situations because they could not adapt and be flexible in a host country. Participants in this study have stated the following:

"If transnational teachers and students are not adequately prepared for their roles, they tend to have a lack of understanding of the host country in general. This can impact seriously on the way the teacher comes across to the student." Academic leader 5.

\section{Theme 4: Challenges related to teaching and learning}

The study also revealed that although partnering institutions strived to maintain high academic standards, there was still a need for modified content, teaching practices and assessment strategies.

"Teaching models are often a problem but our coming to the country prompted a lot of new developments, such as simulation laboratory in Rwanda, telehealth in Rwanda ... new books in the library in all countries visited." Academic leader 1.

Participants in this study were unanimous in this view and stated that most often TNE projects were for profit and were largely unregulated, and as a result, many of the regulated parts suffer 
poor control.

“... The development of TNE is a reality and appropriate criteria to measure quality must be adopted to improve service delivery." Academic leader 2.

\section{Theme 5: Cultural care in TNE}

The following quote from one of the participant's sums up the general consensus of academia, wanting to engage and connect with their students despite cultural differences.

"As an educator, you need to create an environment where your students feel 'safe' in participating." Academic leader 5.

Communication between students and teachers can be affected by cultural norms and values. Participants, felt that proper orientation and a clearly communication of expectations to students from the beginning is vital for a win-win situation.

"You cannot insist on certain type of behavior without and explanation ... this may just make students uncomfortable and they will shut down." Academic leader 3.

\section{Theme 6: Best operating practices}

Participants in this study regarded "good practice" approaches as something that would be learned from co-operation between countries.

"What will be worthwhile to the students is to do a pre-course to help with selection ... they will have a better understanding of what is required of them." Academic leader 3.

\section{TNE GRADUATE RESPONSES}

\section{Theme 1: The distance factor between teacher and student}

The increased distance between the lecturer and the student was viewed as a major problem in the student achieving his or her learning outcomes.

"I had a lot of obstacles because there was very little personal guidance from my lecturer ... your lecturer is supposed to be there to guide and motivate you." Graduate 3.

\section{Theme 2: Learning opportunities}

Peer mentoring was a vital strategy in helping the nursing students to attain their learning outcomes. Peer mentoring was however, not consistent in all institutions and for some nursing students, placement in the clinical environment proved frustrating as they were not given the necessary support and supervision. 
“... the peer mentors actually help when our teachers are not around ... and with their guidance we gradually became competent ... and sometimes experience is the best teacher ... because they were once in our shoes." Graduate 9.

\section{Theme 3: Support structures}

Some graduates in this study verbalized a positive opinion on support that was given during their studies.

"I now realize the importance of having an international curriculum for my employability ...." Graduate 3.

Other students acknowledged the assistance and support of some of the partnering institutions with legal issues. The following response highlights this:

“... bribery and corruption prevented us from getting our academic records from our previous institution ... eventually our facilitator had to contact the Heads of department and send through endorsements which hastened the process." Graduate 9.

Most students failed to understand regulatory and accreditations issues pertaining to TNE in their country. This was highlighted in the following responses:

“... like being told everything on orientation ... whether we are going to get jobs when we go to another country or whether we have to write another exams ... we have a right to know this as we pay a lot of money for the courses." Graduate 5 .

Other graduates felt that although the nursing programmes were at times offered simultaneously in two different continents, difference in educational systems created accreditation problems, causing frustration and delays. Graduates said:

"There should be a general legal framework which could integrate the different educational structures and values of the two countries in issuing the same qualifications ... after all we are doing the same course" Graduate 10.

\section{Theme 4: Group cohesion}

All participants stated that they valued the support they received from fellow students. This increased group morale added to their confidence and abilities.

“... we were from different states but grew close ... my friend was my pillar of strength ... she shared my anxieties, awkward situations, frustrations, moments of confusion and doubt." Graduate 1.

Findings from documentation, reviewed in this study, revealed that the TNE academic programme and quality assurance directives, which should include good practices of "home" and "host" higher education institutions, ensuring individual integrity and institutional 
credibility were evidently lacking. Adamiak and Sauls (2017, 230-248) agree that, cross-border should be a process of integrating an international and intercultural dimension into the teaching, research and service functions of the institution. This should also be reflected in institutional records. This study, however, revealed that although institutional records painted an optimistic and colorful picture of TNE processes, there was no mention of any of the internal or external risk factors that posed a possible challenge to success of the programme delivery. According to Havukainen and Ikonen $(2013,55)$, candidates participating in these programmes need to be informed of possible challenges such as differences in educational systems, government policies, cultural differences, and costs of programme and the nature of delivery. Shaffer and Dukta $(2013,11-16)$ agree that it is imperative that, all partnerships are aware of important policy issues and implications in cross-border nursing education. As global initiatives and collaborative partnerships are developed monitoring and regulating becomes an imperative to avoid mal-functional of administrative processes and system deficits.

\section{DISCUSSION}

\section{Recruitment and selection}

Participant's reflection on their direct experiences with cross-border education revealed that collaborating countries tend to do so, for mutual gains. There was no evidence of centralized selection, recruitment or registration processes during data collection. Institutional internal policies often dictated selection criteria and most policies were tailor-made or suited to the needs of the partnering institutions. Participants strongly felt that the responsibility and accountability in ensuring that cross-border programmes adhere to the necessary quality assurance principles and practices lay with accreditation bodies that govern nursing education and training in the respective countries. Findings in this study, also revealed that TNE programme coordinators and lecturers were not suitably qualified and lacked skill, experience and expertise.

\section{Monitoring and regulatory activities}

It was evident from documentation reviews that although nursing curricula were developed within the home country's educational framework, certain study methods, were based on international nursing models, which posed a direct conflict in the programme facilitation, as it did not reflect the institutional needs, the students or the host country. The study also revealed that although partnering educational institutions, endeavoured to maintain high academic standards, there was still a need to revise and adapt content to suit the needs of partnering 
countries. Findings also revealed that educational institutions were not fully transparent to potential students about what to look for when considering making an application to a transnational provider. Record reviews also revealed that information brochures and pamphlets omitted any information regarding programme accreditation. Graduates also felt that although the nursing programmes were sometimes offered simultaneously in two different continents, differences in the respective country's educational systems and problems with accreditation and programme recognition delayed them from obtaining their qualification and securing employment timeously. These findings further justified the need for monitoring and governance processes of cross-border nursing education programmes.

\section{Support structures}

All participants highlighted the need for proper orientation sessions, workshops and seminars for students and programme coordinators. Other initiatives for students and teachers such as elearning mentorship programmes were considered helpful to facilitate support and promote the teaching/learning process. Participants also stated that, if these initiatives are clearly communicated to all relevant parties, it would help to clarify expectations, policies and thereby, prevent further cross-border challenges. Students noted that, orientation and induction programmes assisted with effective communication, conflict management and time management Other human resources limitations such as lack of transportation also affected the timely acquisition of student learning material such as text-books.

\section{Best operating practices}

The researchers of this article noted that within the transnational teaching environment, there were strengths, limitations and conflicting practices across higher educational institutions. Participants emphasized that cross-border effectiveness must be influenced by intercontinental or international cultural awareness and consideration of cultural diversity when developing policies and practices, will allow the program to be structured according to the cultural orientation of the students and staff alike. The implementation and utilization of current and emerging technologies was another best operating practice that was noted, which was particularly beneficial to students that were engaged in research outputs. It was also noted that e-learning platforms such online student/lecturer classrooms and chat groups, encouraged and facilitated distance learning and online communication between student and lecturer.

The findings of this study also revealed that there is a capacity gap in terms of knowledge, experience and understanding of quality assurance systems which can be regarded as a "hindrance" to the future development and delivery of cross-border nursing education. All 
programs offered should be in line with the institution's vision, mission and philosophies and the same quality assurance principles must be applicable to its satellite learning centres or learning institutions set up elsewhere. Such principles can mean having suitably qualified lecturers or administrators to co-ordinate and facilitate particular programmes and its delivery. Components such as transparency, recognition and accreditation, which the researchers in the current study found to be noticeably fragmented and uncoordinated, have an inherent role in assuring TNE quality.

Commitment to quality by all TNE providers is essential for successful programme delivery. Wilson (2002, 417-426) revealed that, constructive contributions of academic staff are indispensable as they promote quality and social, cultural and linguistic relevance to a crossborder programme, adding value to the qualification standard it offers. Solid structures and governance models in TNE facilitate and foster effective international collaboration and teamwork. They also identify inherent risks to programme delivery, ensuring that systems and processes are made more transparent and comparable to the partnering country expectations. Competition for students in the transnational education arena has intensified and as students are the direct recipients of cross-border nurse education they should carefully scrutinize available information, during the decision-making process (Yeravdekar and Tiwari 2014, 157-172). Therefore, increase in international educational collaboration and partnerships should offer students wider choices, demanding high quality educational programmes from higher education institutions. This so-called this "power" of consumer choice will be a driving force, forcing institutions to consider the quality and value its programmes.

\section{THIS STUDY'S CONTRIBUTION TO KNOWLEDGE}

Cross-border nursing education appears to be the way forward in this century. The findings and lessons learnt in this study signify the increased personal growth, cultural diversity awareness, adaptation to an unfamiliar environment, and increased self-efficacy of all cross-border stakeholders. Adherence to quality assurance practices will benefit the higher education institution, by recognition of its effectiveness and capacity, as quality in teaching and learning is strengthened. These findings, are also relevant, to all higher education institutions engaged in international partnerships related to non-nursing cross-border programs. Further areas for research based on the findings are to explore clinical facilitators' and mentors' experiences with cross-border nursing students and clinical accompaniment. Other suggested research areas stemming from this study, are to examine institutional best operating practices, such as quality assurance programmes, in order to identify if educational institutions are accepting of suggestions and proposed changes. 


\section{CONCLUSION}

Quality nursing education delivery will always remain a main focus in any tertiary institution, where there are possible risks related to inappropriate deliveries of teaching and learning programmes in off-shore environments. The global education market is changing rapidly and new global educational alliances are being formed. Whether TNE is a way of increasing education availability, a stricter control approach and regulation on the quality assurance operations of TNE does not seem to be inconvenient. It is therefore quite obvious that TNE will remain a critical part of the international higher education agenda for many years to come and collaborative partnerships will be committed to supporting their potential partners in the development and delivery of quality nurse education.

This research provided a platform for graduates to lend their voices to promoting crossborder nursing education delivery and suggests that although international collaborations endeavour to maintain high academic standards in TNE, there is still a need to re-engineer, revise and adapt curricular content, learning, teaching and assessment practices. It is therefore hoped, that this research article, will offer guidance to forthcoming and existing higher education curriculum developers who plan to engage in national or international educational partnerships.

\section{REFERENCES}

Adamiak, J. P. and R. D. Sauls. 2017. Influencing mathematics students' academic success through online intervention: A case study. South African Journal of Higher Education 31(3): 230-248. http://dx.doi.org/10.20853/31-3-1573 (Accessed 15 March 2018).

Adam, S. 2001. Transnational Education Project Report and Recommendations. University of Westminster.

Armstrong, S. and Rispel. 2015. Social accountability and nursing education in South Africa. Global Health Action Special Issue. Transforming Nursing in South Africa 8: 5-13. http://www. globalhealthaction.net (Accessed 26 May 2018).

Baumann, A. and J. Blythe. 2008. Globalization of higher education in nursing. The Online Journal of Issues in Nursing 13(2): 4-5.

Burnett, S. A. 2008. The impact of globalization on higher education institutions in Ontario. Doctor of Business Administration (Higher Education Management). University of Bath. United Kingdom.

Collins, S. and I. Hewer. 2014. The impact of the Bologna process on nursing higher education in Europe: A review. International Journal of Nursing Studies 51: 150-156. https://www.journal ofnursingstudies.com/article/pdf (Accessed 26 May 2018).

Chetro-Szivos, J. 2010. Cross-border tertiary education: Challenges and opportunities for intercultural understanding. Journal of Intercultural Management 2(1): 5-22.

Department of Higher Education and Training see Republic of South Africa.

Dominguez-Whitehead, Y. and N. Sing. 2015. International students in the South African higher education system: A review of pressing challenges. South African Journal of Higher Education 29(4): 77-95. https://journals.co.za/content/high/29/4/EJC182455 (Accessed 20 March 2018). 
Edmonds, M. L. 2010. The lived experience of nursing students who study abroad: A qualitative inquiry. Journal of Studies in International Education 14(5). http://jsie.sagepub.com (Accessed 26 May 2018).

Fearnside, R. and K. Chung. 2017. Cross-border quality assurance: Case study of Hong Kong and Macao. Higher Education Evaluation and Development 11(2): 81.

Gamage, D. T., J. Suwanabroma, T. T. Ueyama, S. Hada and E. Sekikawa. 2008. The impact of quality assurance measures on student services at the Japanese and Thai private universities. Quality Assurance in Education 16(2): 181-198. http://doi.org/10.1108/09684880810868457 (Accessed 20 February 2018).

Havukainen, P. and T. Ikonen. 2013. Transatlantic dual degree program in nursing. Laurea Publications 16. (Accessed 24 February 2016).

Knight, J. 2004. Internationalization remodelled: Rationales, strategies and approaches. Journal of Studies in International Education 8(1): 21.

Knight, J. 2006. Cross-border education: Programs and providers on the move. Canadian Bureau for International Education 10: 1-28.

Lafond, C. and Vincent, C. van Hulle. 2012. A critique of the National League for Nursing/Jeffries simulation framework. Journal of Advanced Nursing 69(2).

Lee, Y. H., T. Chiang and C. T. Liu. 2017. Residents' educational attainment and preventive care utilization in China. International Journal of Health Care Quality Assurance 38(1): 41-51. https://doi.org/10.1108/IJHCQA-01-2017-0001 (Accessed on 25 February 2018).

Nguyen, T. 2012. Internal quality assurance in Vietnam's higher education: The influence by international projects, evaluation and assessment. Master of Science in Education Science and Technology. University of Twente.

Polit, D. F. and C. T. Beck. 2012. Nursing research: Generating and assessing evidence for nursing practice. $9^{\text {th }}$ Edition. Philadelphia: Lippincott Williams and Wilkins.

Ralarala, M. K., E. A. Pineteh and Z. Mchiza. 2016. A case study on the language and socio-cultural challenges experienced by international students studying at Cape Peninsula University of Technology. South African Journal of Higher Education 30(4): 231-253. http://dx.doi.org/ 10.20853/30-4-572 (Accessed 15 March 2018).

Republic of South Africa. Department of Higher Education and Training. 1997. Higher Education Act 101 of 1997. http://www.dhet.gov.za/ (Accessed 4 May 2016).

Rumbley, L. E., P. G. Altbach and L. Reisberg. 2012. Internationalization within the higher education context. The Sage Handbook of International Higher Education. Thousand Oaks, Sage. London.

Shaffer, A. F. and J. T. Dutka. 2013. Global mobility for internationally educated nurses: Challenges and regulatory implications. Journal of Nursing Regulation 4(3): 11-16.

Sooryamurthy, R. 2013. Scientific collaboration in South Africa. South African Journal of Science 109(5/6): 1 .

Van Niekerk, M. P. and L. Schmidt. 2016. The ecology of distance learning: Bridging the gap between university and student. South African Journal of Higher Education 30(5): 196-214. http://dx.doi.org/10.20853/30-5-663 (Accessed 9 March 2018).

Villanueva, N. N. 2012. Assuring quality in Belizean higher education: A collective case study of institutional perspectives and practices. Doctor of Philosophy. University of Nebraska.

WHO see World Health Organization

Wilson, M. 2002. Transnational nursing programs: Models, advantages and challenges. Nursing Education Today 22(5): 417-426.

World Health Organization. 2013. Transforming and scaling up health professional education and training. Policy brief on accreditation of institutions for health professional education. WHO, Geneva. http://whoeducationguidelines.org/sites/ (Accessed 31 March 2016).

Yeravdekar, V. R. and G. Tiwari. 2014. Internationalization of higher education in India: How primed 
is the country to take on education hubs? Procedia-Social and Behavioural Sciences 157: 172.

Zeleza, P. T. 2012. Internationalization in higher education: Opportunities and challenges for the knowledge project in the Global South. Vice-Chancellors Leadership Dialogue. Loyola Marymount University. Los Ange. California. 